\title{
Corrigendum: A review of higher order aberrations of the human eye
}

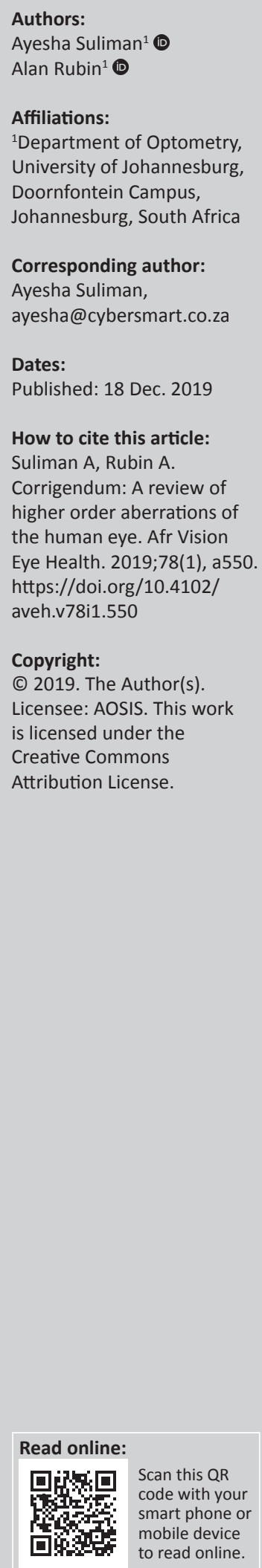

${ }^{1}$ Department of Optometry, University of Johannesburg, Doornfontein Campus, Johannesburg, South Africa

\section{Corresponding author:} Ayesha Suliman, ayesha@cybersmart.co.za

Dates:

Published: 18 Dec. 2019

How to cite this article:

Suliman A, Rubin A.

Corrigendum: A review of

higher order aberrations of the human eye. Afr Vision Eye Health. 2019;78(1), a550. https://doi.org/10.4102/ aveh.v78i1.550

\section{Copyright:}

(C) 2019. The Author(s). Licensee: AOSIS. This work

is licensed under the

Creative Commons

Attribution License.

In the original article published, the category heading was incorrectly labelled as 'Original Research'. The correct category heading, therefore, is as follows: 'Review Article'. The authors apologise for any inconvenience caused. 